\title{
A Comprehensive Analysis of Light Weight Steel Structure and Wind Load
}

\author{
Nitin Khare ${ }^{[1]}$, Dr Rajeev Chandak ${ }^{[2]}$ \\ ${ }^{[1]}$ Postgraduate Student, Department of Civil Engineering, Jabalpur Engineering College, Jabalpur, Madhya \\ Pradesh, India \\ ${ }^{[2]}$ Professor, Department of Civil Engineering, Jabalpur Engineering College, Jabalpur, Madhya Pradesh, India \\ *Corresponding e-mail : nitin.khare21@gmail.com
}

\begin{abstract}
Article Info

Volume 8, Issue 6

Page Number : 396-403

\section{Publication Issue}

November-December-2021

\section{Article History}

Accepted : 05 Dec 2021

Published : 16 Dec 2021

Review to hot-rolled steel structures, cold-formed steel structures are susceptible to extreme winds because of the light weight of the building and its components. Many modern cold-formed steel structures have sustained significant structural damage ranging from loss of cladding to complete collapse in recent cyclones. This article first provides Review some real damage cases for light steel structures induced by the high winds. After that, the paper reviews research on the damage analysis and evaluation of light steel structures caused by strong winds, which include connection failure, fatigue failure, purlin buckling, and primary frame component instability problems. Moreover, this review will mention some applications of structure damage assessment methods in this area, such as vulnerability analysis and performance-based theory, etc.

Keywords: Damage, Light Steel Structures, Cladding, Purlin, Wind Hazards
\end{abstract}

\section{INTRODUCTION}

Sustainable development and energy efficiency are two of the most relevant concerns of today's humankind. Therefore, the demand to reduce energy consumption and to use more environmental friendly materials is increasing. In fact, today there is no doubt about the link between the burning of fossil fuels and the consequent release of carbon dioxide with climatic changes, for example, global warming and extreme climate events. Buildings exhibit an enormous potential to mitigate greenhouse gas (GHG) emissions when compared with other activity sectors [1]. Thus, the use of renewable energy sources (RES) and the reduction of energy consumption are two top priorities, being these the major challenges of the twenty-first century for emerging and developed countries.

In this context, several objectives were established by the European Union in the Energy Performance Building Directive-EPBD (European Directive 2010/31/EU [2]) regarding "nearly zero-energy buildings" for the year 2020. The EPBD addressed 
both the increase in RES and the improvement in buildings energy efficiency.

Several alternatives to traditional reinforced concrete structure and brick wall buildings have emerged, including the lightweight steel-framed (LSF) buildings. Given its advantages (economical, functional, environmental, etc.), the market share of LSF construction system grew significantly, mainly in low-rise residential buildings, making this kind of construction more attractive and popular [3]. Some of these advantages are as follows: high architectural adaptability [4, 5]; reduced weight; cost-efficiency [6]; exceptionally solid relative to weight; rapid on-site erection; excellent stability of shape in case of humidity; easy to prefabricate; and great potential for recycling and reuse, increasing building sustainability $[1,3,7]$. Section 2 of this chapter presents a brief overview of the LSF construction system, which includes the materials used, its classification regarding the position of thermal insulation, and the methods for manufacturing and framing.

\section{LITERATURE REVIEW}

PabloJaen-Sola, Lightweight design of direct-drive wind turbine electrical generators: A comparison between steel and composite material structures: Direct-drive generators for wind turbines are high torque, low speed machines which require a heavy robust structure to maintain the air-gap clearance open and stable. The mass of the structural material can be assessed at the early stages of the design process for radial-flux generators. By using low density materials, such as composites, the entire mass of the machine can be significantly reduced. A comparison between steel structures and structures made with composite materials working under the same loading conditions is made using small scale $(100 \mathrm{~kW})$ and large scale (3 MW) generator models. Potential improvements to the lightweight proposed structures are also suggested [1].

TianlinZhong, Mechanical properties of lightweight 316L stainless steel lattice structures fabricated by selective laser melting: The performance of advanced and lightweight 316L stainless steel lattice structures fabricated by selective laser melting (SLM) was investigated using a range of laser energy densities (LED). A unique tetrakaidecahedron cell type was designed to construct a periodic lattice structure, which was compared with two common lattice structures of different unit cell topologies and deformation behaviors using mechanical property and quasi-static energy absorption. It was found that tetrakaidecahedron structure deserved good compressive properties and energy absorption capabilities. The fabricated strut morphology and internal porosity were investigated using confocal and scanning electron microscopy to correlate with the compressive properties of the structure. The porosity was found to increase firstly and then fluctuate smoothly with increasing LED, similar to yield strength. The yield strength and compression modulus were not independent of porosity, indicating that further improvements can be achieved by SLM process optimization. Meanwhile, nonlinear finite element analysis was used to analyze their compressive response and fracture behavior. Our results highlighted that a high performing unit cell geometry can be used for energy absorption and lightweight manufacturing applications of lattice structures [2].

W.J.Lu, Influence of $\kappa$-carbide interface structure on the formability of lightweight steels: $\kappa$-Carbide $(\kappa)$ in high aluminium (Al) steels is grown from austenite $(\gamma)$ via $\gamma \rightarrow \gamma+\kappa$ or $\gamma \rightarrow \alpha+\kappa$ ( $\alpha$ represents ferrite), and is a lamellar structure. This work demonstrates that the formability of high $\mathrm{Al}$ lightweight steels is affected by the lattice misfit and interface shape between $\kappa$ and matrix. The cold workability can be improved by either to change the steel chemical constitution or to implement an electro-thermomechanical process. For ferrite-matrix-based high $\mathrm{Al}$ steel, electric-current promotes the spheroidization and refinement of $\kappa$ structure and reduces volume 
fraction of $\kappa$ phase. This retards the crack nucleation and propagation, and hence improves the materials formability. The observation is caused by a direct effect of electric-current rather than side effects [3].

K.M.A.Sohel, Behavior of Steel-Concrete-Steel sandwich structures with lightweight cement composite and novel shear connectors: In SteelConcrete-Steel (SCS) sandwich structure, mechanical shear connectors are commonly used to transfer longitudinal shear forces across the steel-concrete interface. In this paper, novel shear connectors such as J-hook and cable shear connectors are proposed and their performance to achieve composite strength of SCS sandwich structures is investigated. The use of these connectors together with ultra-lightweight cement composite core reduces the overall weight of SCS sandwich system making it suitable for the construction of marine and offshore structures. Static tests were carried out on SCS sandwich beams with Jhook, cable shear connectors and headed studs. Their ultimate strengths were reported and their respective failure modes were discussed. An analytical method to predict the ultimate strength of the SteelConcrete-Steel sandwich beams with various types of shear connectors was developed and its accuracy was ascertained by comparing with the test results. Deign recommendations are made on minimum connector spacing to prevent shear cracking of concrete core and local buckling of face plates [4].

Chan-YoungLee, Coupled strengthening in a medium manganese lightweight steel with an inhomogeneously grained structure of austenite: The deformation mechanism of a medium-Mn lightweight steel with an inhomogeneously grained structure of austenite was investigated as a function of annealing temperature. All annealed specimens exhibited three different phases: $\gamma$-austenite, $\delta$-ferrite and $\quad \alpha^{\prime}$-martensite. Specimens annealed at temperatures below $1000{ }^{\circ} \mathrm{C}$ exhibited high strainhardening rates (SHRs) and good combinations of ultimate tensile strength and ductility $(\sim 35,000$ $37,000 \mathrm{MPa} \%)$ due to the sequential occurrence of transformation-induced plasticity (TRIP)

and twinning-induced plasticity (TWIP) during tensile deformation. The SHR-true strain curves of the annealed specimens are divided into four different stages: dynamic recovery of dislocations (stage I), active TRIP (stage II), slow TRIP (stage III) and mechanical twinning (stage IV). However, the specimen annealed at $1000{ }^{\circ} \mathrm{C}$ did not exhibit stage IV, most likely due to its coarse grain size. Whereas the TRIP occurred in coarse $\gamma$-austenite grains at small tensile strains, the TWIP took place in fine $\gamma$ austenite grains with a size of less than $\sim 10 \mu \mathrm{m}$ at large tensile strains. This result indicates that grain refinement induced the transition in deformation mechanism from the TRIP to the TWIP. The inhomogeneously grained structure of $\gamma$-austenite in the annealed specimens consists of coarse grains preexisting in the hot-rolled state and fine grains newly formed during annealing [5].

GersonMeschut, Hybrid Technologies for Joining Ultra-high-strength Boron Steels with Aluminum Alloys for Lightweight Car Body Structures: Lightweight design in car body engineering enables the reduction of energy consumption and greenhouse gas emissions of cars, which is crucial to fulfill the increasing legislative restrictions and market demand for eco-friendly mobility. The challenge is to realize more lightweight and at the same time still rigid and crash-stable car bodies, that are affordable for a largescale production. For cars for high volume markets, an intelligent load-oriented multi-material design with intensive use of ultra-high-strength hot-stamped boron steels combined with modern aluminum alloy sheets and cast is often the optimal solution, as these materials offer a great weight reduction potential at reasonable costs. The lack of suitable cost-efficient joining technologies for these material combinations is one of the most important barriers for the realization of affordable cars in volume productions. This paper presents and overview about recent developments and research results for suitable joining technologies [6]. 
Sura A.Zaid, Effect of reinforcement on the performance of steel tubular truss girder infilled with lightweight concrete: This research investigated the performance of lightweight concrete infilled inside steel tubular truss girders. Six specimens of lightweight concrete infilled steel tubular (LWCFST) truss girders were tested. The main variables were the effect of the existence of concrete within the chords and the reinforcing steel bars added into the bottom chord. The lightweight concrete in the bottom chord was reinforced with one or two bars with a nominal diameter of $10 \mathrm{~mm}$, whereas the concrete in the top chord was remained unreinforced. This study demonstration the ultimate loads, flexural strength, load-displacement curves at the mid-span, longitudinal strain curves for chords at mid-span, deflections along the span, and the modes of failure of the tested specimens. The results showed that the existence of the lightweight concrete into the chords increases the strength of the LWCFST truss girder by about $41.2 \%$, also gives them better ductility as compared to the hollow truss girder, and was increased by about $7.6 \%$ to $24.8 \%$ when added reinforcing to concrete in the bottom chord. The adding of reinforcement to the lower of the bottom chord gives the best increase in the ultimate load [7].

SaeedTaali, Architectured lightweight steel composite: evaluation of the effect of geometrical parameters and annealing treatments on deformation behavior: Architectured lightweight steel composites were designed and fabricated through the cold roll bonding (CRB) of stacked steel-aluminum sheet layers. The effects of geometrical parameters including thickness ratio (TR) and the number of constituent layers on bond strength and tensile properties of the composites were evaluated using peeling and tensile tests. It was found that by decreasing the TR of aluminum to steel from 0.5 to 0.2 , the bond strength increased in the as-rolled specimen. However, it led to a decrease in the bond strength of the annealed sample by the facilitation of the formation of $\mathrm{Fe}-\mathrm{Al}$ intermetallics along the interfaces. In order to obtain a more in-depth understanding of deformation behavior at the interface of steel/aluminum layers, strain gradient at these regions was evaluated through the measurement of dislocation density using the XRD analysis. Macrotexture measurement and anisotropy analysis were also carried out to evaluate the formability of the optimized sample. Moreover, it was found that by increasing the number of layers, the bond strength decreased due to the insufficient extrusion of the virgin metals to the interface of the layers. Higher steel/aluminum interfaces as effective microstructural heterogeneities improved the elongation in fivelayered and seven-layered composites by arresting the propagating cracks. Employing the concept of laminated composite led to the production of a lightweight architectured steel with density of

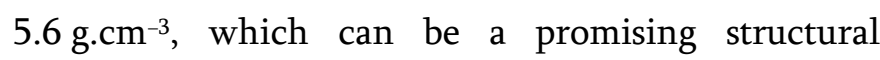
material for automotive applications [8].

XuLingLiujing, - Analysis on housing system of lightweight steel structures and joint connection behavior: The chapter analyzes the property and applicability of housing system of lightweight steel structures in the country. The chapter emphasizes that a joint design is very important in the houses of lightweight steel structures, by analyzing the behavior of a rigid and semi-rigid joint. It emphasizes that the flexibility of a semi-rigid connection decreases the constraining rigidity of beams to columns, and the connecting frame joint has a strong energy consumption behavior which is good for earthquake proof and is considered as an ideal joint form for earthquake proof.The research development and application of housing system of lightweight steel structures can promote industrialization and standardization of the housing construction, accelerate steel structures instead of brick-tile construction, and construct green environmental buildings. Researching the practical deformation behavior of the joint area, and designing safe, reliable, 
reasonable, and economical steel frame joint connection is important [9].

Y.X.Chen, Development of cement-free bio-based cold-bonded lightweight aggregates (BCBLWAs) using steel slag and miscanthus powder via $\mathrm{CO}_{2}$ curing: Bio-based lightweight aggregates are a novel type of lightweight aggregates. The use of plant-based aggregates in concrete effectively decreases its bulk density, the environmental impact and improve the thermal insulation property. However, the application of plant-based aggregate in ordinary cement-based concrete still faces critical problems, for instance, the polysaccharide leached from the plant retards the hydration of clinker and lead to degradation of concrete strength. In this study, a novel bio-based cold-bonded lightweight aggregates (BCBLWAs) was developed with the use of converter steel slag and miscanthus powder via $\mathrm{CO}_{2}$ curing. The aggregates using steel slag as a binder show relatively high strength and low density with the use of miscanthus. The polysaccharide leached from miscanthus powder, which negatively influences the cement-based aggregates, has no influence on the artificial carbonated steel slag aggregate. The developed BCBLWAs obtained compressive strengths from $0.58 \mathrm{MPa}$ to $5.3 \mathrm{MPa}$ and loose bulk densities from $550 \mathrm{~kg} / \mathrm{m}^{3}$ to $1300 \mathrm{~kg} / \mathrm{m}^{3}$. The reaction products and microstructure of BCBLWAs after carbonation curing were characterized by TGA, XRD, SEM and nitrogen physisorption. The $\mathrm{CO}_{2}$ uptake capacity of BCBLWAs was also evaluated. Furthermore, the prepared BCBLWAs were utilized to prepare a lightweight concrete, which obtained optimal compressive strength $(28.5 \mathrm{MPa})$, dry bulk density $\left(1630 \mathrm{~kg} / \mathrm{m}^{3}\right)$ and thermal insulation $(0.439 \mathrm{~W} /(\mathrm{m} \cdot \mathrm{K}))$. The effect of BCBLWAs on the hydration of cement was also evaluated to be minor and only showed a slight retardation effect. The lowest thermal insulation of BCBLWAs incorporated lightweight concrete reached $0.255 \mathrm{~W} /(\mathrm{m} \cdot \mathrm{K})[10]$.
ChunzeYan, Advanced lightweight 316L stainless steel cellular lattice structures fabricated via selective laser melting: This paper investigates the manufacturability and performance of advanced and lightweight stainless steel cellular lattice structures fabricated via selective laser melting (SLM). A unique cell type called gyroid is designed to construct periodic lattice structures and utilise its curved cell surface as a self-supported feature which avoids the building of support structures and reduces material waste and production time. The gyroid cellular lattice structures with a wide range of volume fraction were made at different orientations, showing it can reduce the constraints in design for the SLM and provide flexibility in selecting optimal manufacturing parameters. The lattice structures with different volume fraction were well manufactured by the SLM process to exhibit a good geometric agreement with the original CAD models. The strut of the SLMmanufactured lattice structures represents a rough surface and its size is slightly higher than the designed value. When the lattice structure was positioned with half of its struts at an angle of $0^{\circ}$ with respect to the building plane, which is considered as the worst building orientation for SLM, it was manufactured with well-defined struts and no defects or broken cells. The compression strength and modulus of the lattice structures increase with the increase in the volume fraction, and two equations based on Gibson-Ashby model have been established to predict their compression properties [11].

C.D.Horvath, 2 - Advanced steels for lightweight automotive structures: High strength steels are commonly used in the automotive industry to reduce mass and improve structural performance. This chapter discusses the history of steel in the manufacture of automobiles, the types of steels currently being used and the new advances in the types of steels that can be used for lightweighting automotive structures. The chapter also reviews the manufacturing and forming aspects of these steels 
along with some design considerations for the selection of these materials [12].

M.Eskandari, Potential application of nanocrystalline 301 austenitic stainless steel in lightweight vehicle structures: In recent years, nano/ultrafine grained steels have been the focus of great attention for the construction of lightweight structures. In this work, the effects of thermo-mechanical parameters were investigated in order to achieve a nanocrystalline structure in the as-cast AISI 301 stainless steel. A minimum grain size of $18 \mu \mathrm{m}$ was initially achieved when homogenization took place at $1200{ }^{\circ} \mathrm{C}$ for $9 \mathrm{~h}$ followed by hot rolling at a temperature range of $1000-1200^{\circ} \mathrm{C}$ with a strain value of 0.8 and a strain rate of $1.2 \mathrm{~s}^{-1}$. The product was then annealed at $1050{ }^{\circ} \mathrm{C}$ for $3 \mathrm{~min}$. In order to get a nanocrystalline structure, repetitive cold rolling followed by subsequent annealing was used. The cold rolling was carried out at a temperature of $-10{ }^{\circ} \mathrm{C}$ with a strain rate of $0.5 \mathrm{~s}^{-1}$ and a reduction of $95 \%$, while the annealing treatment was conducted at temperatures of 600 to $850{ }^{\circ} \mathrm{C}$ for 0.5 to $50 \mathrm{~min}$. The results showed that the nanocrystalline austenitic structure with a grain size of about $70 \mathrm{~nm}$ was obtained by annealing at $850{ }^{\circ} \mathrm{C}$ for $1 \mathrm{~min}$ after an overall cold rolling reduction of $95 \%$ [13].

K.I.Christidis, Flexural behaviour of pumice lightweight concrete reinforced with end-hooked steel fibres: A study on the mechanical properties of end-hooked steel-fibre reinforced pumice lightweight concrete is presented. Typical compression and threepoint bending tests were performed in a reference lightweight concrete batch, where two different steel end-hooked fibres were added in four different contents $0.5 \%, 0.75 \%, 1.0 \%$, and $1.5 \%$ per volume. The experimental results were evaluated in both strength and deformation terms and further processed, in order to illustrate the influence of fibres to the strength and deformation capacity, in correlation to the geometrical aspect ratio and the volume fraction of the fibres. Compressive strength, but mainly flexural strength was found to be significantly enhanced, especially, in terms of post crack behaviour. An effort to model the post-crack behaviour in flexure was also conducted. A multi-phase constitutive law is proposed which describes the Stress - Crack Mouth Opening Displacement behaviour of steel-fibre reinforced pumice lightweight concrete in correlation to the mechanical properties of plain lightweight concrete [14].

GokhanKaplan, Effect of high volume fly ash and micro-steel fiber on flexural toughness and durability properties in self-compacting lightweight mortar (SCLM): In this study, high volumes of fly ash and micro-steel fiber were used to improve lightweight aggregate mixes' strength and durability properties that can be used in the prefabrication industry. The developed composite can be used in roof truss flooring of steel structures and bridge decks. Although the unit weight of the mixtures was reduced below $2000 \mathrm{~kg} / \mathrm{m}^{3}$, micro steel fibers were used to improve the behaviour against seismic effects. The increase in fly ash content increased the porosity, water absorption, and water penetration depths of the mixes. The increase in the steel fiber content created a micro-filter effect, reducing the water absorption and water penetration depths. The hardened unit weights of the mixes vary between $1305-1723 \mathrm{~kg} / \mathrm{m}^{3}$, while their 91-day compressive strength varies between 30.9 and $46.4 \mathrm{MPa}$. It has been observed that the mixes using steel fiber are in the medium and good class in the residual strength factors specified in ASTM C 1018. The carbonation depth of the mixes using 50\% fly ash increased more than 5.5 times compared to the reference mix. After the freeze-thaw effect, spills occurred on the surfaces of the mixes due to fiber corrosion [15].

\section{LSF CONSTRUCTION SYSTEM}

This section provides a brief description of the lightweight steel-framed (LSF) construction system. First, an overview of the main materials used in this construction system (structural cold-formed steel 
sections, sheathing panels and insulation materials) is presented. It continues with the typical classification of LSF construction components, concerning that the thermal insulation location within these components is described and concludes with a concise overview of the manufacturing processes and the framing methods.

\section{CONCLUSIONS}

Light steel structures are especially susceptible to extreme winds because of the light weight of the building and its components. Research on this topic has been conducted around the world for several decades. There are still some problems that need to be further studied on limit states about claddings, purlins, and mainframes. Moreover, it is necessary to make a precise prediction for the response of real light steel structures under extreme wind loads. For cladding connections, previous studies only focused on the static and fatigue performance of the screw connection. However, the evolution of crack damage and the degradation or deterioration of connections induced by fatigue could be next research point. For purlin sheeting systems, previous research concentrated on the stress distribution of prebuckling and limit states of buckling for purlins. The sensitivity of restraint to the limit states of the purlins the damage assessment such as strength or bending stiffness reduction could also be a new research point to be analyzed. For the light steel structure frames, previous literature presents some work on understanding the interactions between cladding support and main resistant frames. As a result, it is crucial for advancing cold-formed steel design to the next stage. Performance-based wind engineering methodologies for cold-formed light-frame steel construction are currently unavailable. Performance goals, limit states levels, time-dependent reliability theory, and fragility analysis for the cold-formed steel structural systems exposed to wind hazard could also be the significant research points to be studied in the future.

\section{REFERENCES}

[1]. PabloJaen-Sola, Lightweight design of directdrive wind turbine electrical generators: A comparison between steel and composite material structures, Ocean Engineering, Volume 181, 1 June 2019, Pages 330-341,

[2]. TianlinZhong, Mechanical properties of lightweight 316L stainless steel lattice structures fabricated by selective laser melting, Materials \& Design, Volume 181, 5 November 2019, 108076.

[3]. W.J.Lu, Influence of $\kappa$-carbide interface structure on the formability of lightweight steels, Materials \& Design, Volume 104, 15 August 2016, Pages 211-216.

[4]. K.M.A.Sohel, Behavior of Steel-Concrete-Steel sandwich structures with lightweight cement composite and novel shear connectors, Composite Structures, Volume 94, Issue 12, December 2012, Pages 3500-3509.

[5]. Chan-YoungLee, Coupled strengthening in a medium manganese lightweight steel with an inhomogeneously grained structure of austenite, Acta Materialia, Volume 84, 1 February 2015, Pages 1-8.

[6]. GersonMeschut, Hybrid Technologies for Joining Ultra-high-strength Boron Steels with Aluminum Alloys for Lightweight Car Body Structures, Procedia CIRP, Volume 23, 2014, Pages 19-23.

[7]. Sura A.Zaid, Effect of reinforcement on the performance of steel tubular truss girder infilled with lightweight concrete, Materials Today: Proceedings, Available online 7 November 2021.

[8]. SaeedTaali, Architectured lightweight steel composite: evaluation of the effect of geometrical parameters and annealing treatments on deformation behavior, Journal of Materials Research and Technology, Volume 
15, November-December 2021, Pages 54145427.

[9]. XuLingLiujing, - Analysis on housing system of lightweight steel structures and joint connection behavior, Fourth International Conference on Advances in Steel Structures Proceedings of the Fourth International Conference on Advances in Steel Structures 1315 June 2005, Shanghai, China, Volume I, 2005, Pages 875-880.

[10]. Y.X.Chen, Development of cement-free biobased cold-bonded lightweight aggregates (BCBLWAs) using steel slag and miscanthus powder via $\mathrm{CO} 2$ curing, Journal of Cleaner Production, Volume 322, 1 November 2021, 129105.

[11]. ChunzeYan, Advanced lightweight 316L stainless steel cellular lattice structures fabricated via selective laser melting, Materials \& Design, Volume 55, March 2014, Pages 533541.

[12]. C.D.Horvath, 2 - Advanced steels for lightweight automotive structures, Materials, Design and Manufacturing for Lightweight Vehicles, Woodhead Publishing Series in Composites Science and Engineering , 2010, Pages 35-78.

[13]. M.Eskandari, Potential application of nanocrystalline 301 austenitic stainless steel in lightweight vehicle structures, Materials \& Design, Volume 30, Issue 9, October 2009, Pages 3869-3872.

[14]. K.I.Christidis, Flexural behaviour of pumice lightweight concrete reinforced with endhooked steel fibres, Structures, Volume 33, October 2021, Pages 3835-3847.

[15]. GokhanKaplan, Effect of high volume fly ash and micro-steel fiber on flexural toughness and durability properties in self-compacting lightweight mortar (SCLM), Construction and Building Materials, Volume 307, 8 November 2021, 124877.

\section{Cite this article as :}

Nitin Khare, Dr. Rajeev Chandak, " A Comprehensive Analysis of Light Weight Steel Structure and Wind Load ", International Journal of Scientific Research in Science and Technology(IJSRST), Print ISSN : 23956011, Online ISSN : 2395-602X, Volume 8, Issue 6, pp.396-403, November-December-2021. Available at doi $\quad:$ https://doi.org/10.32628/IJSRST218650 Journal URL : https://ijsrst.com/IJSRST218650 